\title{
NOTAS
}

\section{Enrique Fuentes Quintana. Mis recuerdos del profesor y del economista}

\section{Adolfo Rodero Franganillo'}

Con este breve escrito, no pretendo realizar un relato biográfico de Enrique Fuentes Quintana. En numerosos medios, han aparecido textos que han tratado de forma exhaustiva la vida de Fuentes. Mi pretensión es más modesta: recoger, aunque sea de forma dispersa, mis recuerdos del profesor y del economista.

Conocí a D. Enrique cuando yo cursaba la licenciatura de ciencias económicas en la Universidad Complutense de Madrid. Era el profesor de Hacienda Pública, asignatura que en dos años impartía un curso de sistema fiscal, del que se responsabilizaba principalmente Cesar Albiñana, recientemente desaparecido, y un curso de hacienda pública propiamente dicha (con partes dedicadas a la política fiscal, a los ingresos públicos, etc.) que explicaba Fuentes; su proyecto como docente iba sin embargo más allá; según sus propias palabras, trataba de llenar las muchas lagunas que existían en la formación que recibíamos los futuros economistas. Efectivamente, nos enseñó teorías, análisis, escuelas que nos proporcionaron una base amplia de la ciencia económica. Una muestra del valor que dábamos a su enseñanza, es que cuando organizó un seminario voluntario para los alumnos que estábamos terminando la licenciatura consiguió un gran éxito de asistencia. ¡Dudo que en la actualidad tuviera igual resonancia una actividad que no afectaba a la calificación de una materia!

En esta época, se elaboró el Plan de Estabilización de la economía española que dio lugar a la modernización de la economía franquista. En su redacción tuvo un importante papel Fuentes Quintana por lo que su eco entre los estudiantes fue muy amplio; recuerdo que los documentos del Plan eran "perseguidos" en la Facultad como una importante aplicación de las teorías que estudiábamos en los libros.

También en el plano editorial de aquellos años, tuvo Fuentes un relevante protagonismo. En el pobre panorama de entonces, destacó una revista Información Comercial Española en la que un conjunto de economistas, principalmente Fuentes y otros profesores de la Facultad, le dieron nuevos contenidos y un nivel muy apreciable. Esta fue probablemente su primera aventura editorial que luego continuaría con otros muchos títulos.

' Profesor de la Facultad de Ciencias Económicas y Empresariales - ETEA. 
Un recuerdo más personal es el que se refiere al programa de doctorado que cursé. El profesor Rojo deseaba que los cursos de doctorado se tomasen en serio y que no fuesen un mero trámite. Elaboró un programa en el que participó un conjunto de prestigiosos economistas: Fuentes, Varela, Martínez Cortiña y otros. Su alto nivel reproducía en parte la enseñanza de la London School of Economics que había seguido Luis Angel Rojo. La aportación de Fuentes, Rojo y los demás profesores fue para los alumnos de doctorado una revelación sobre la profundidad de la ciencia económica.

Asimismo, Rojo, mi maestro en mis inicios como economista, dirigió mi tesis doctoral que fue defendida ante un tribunal en el que participó Enrique Fuentes.

Ya en la democracia, es muy conocido el papel protagonista que Fuentes Quintana, ministro de Economía, tuvo en la elaboración de los Pactos de la Moncloa. El maestro era ahora también un gran político, que aunque lo fue durante poco tiempo, dejó una huella muy profunda en la política española.

Su actuación política lo alejó temporalmente de los medios universitarios, aunque enseguida su participación en la Fundación para la Investigación Económica y Social de la Confederación de Cajas de Ahorro fue unida a una importante actividad investigadora. Sus artículos sobre la economía española publicados en el diario El País eran esperados con la máxima expectación por muchos economistas que encontrábamos en ellos el mejor análisis de la coyuntura económica. En esta etapa, tuvo una intensa actividad editorial: la creación de Papeles de Economía Española, leída por casi todos los economistas, con su siempre interesante aportación en los editoriales de cada número, las Perspectivas del Sistema Financiero, de carácter más especializado y otros títulos siempre en el marco de la Fundación.

Entre los muchos actos que protagonizó recuerdo dos especialmente a los que asistí: a) una reunión sobre tablas "input output", a la que asistieron todos los economistas españoles sobre esta técnica, muy en boga en aquel momento, con la presencia de su creador el profesor americano W. Leontief; b) la conferencia que impartió en la reunión anual de ASEPELT (la Asociación de Economía Aplicada) en Cádiz, en 1993, que desde mi punto de vista, es la mejor interpretación que he escuchado sobre la economía española durante la democracia.

También en la Facultad de Empresariales-ETEA, de la que he sido profesor durante muchos años, tenemos recuerdos de Fuentes; sólo apuntaré algunos de ellos: a) en los primeros tiempos de la Fundación de las Cajas, se realizaron periódicamente análisis de coyuntura de los diferentes sectores económicos; en ETEA nos encargamos de uno de ellos y tuvimos reuniones trimestrales durante varios años, presididas por Fuentes; b) asimismo, en 1978, la Fundación de las cajas nos contrató, como resultado de un concurso, para la realización de una investigación sobre "El desarrollo de Andalucía y la función de las cajas de ahorro"; Fuentes como máximo responsable de la Fundación supervisó la realización del estudio; recuerdo una reunión en la que D. Enrique hizo una crítica muy estricta de su contenido que nos sirvió para perfeccionarlo y mejorarlo; así su redacción final fue deudora, en gran parte, del profesor Fuentes; c) por último, en los años noventa, impartió una conferencia en la Facultad sobre la economía española; en estos años, en la que la asistencia a las conferencias suele ser tan escasa, Fuentes consiguió un lleno "hasta la bandera". 
La presencia de Fuentes en ETEA no se limita, sin embargo, a lo indicado. Sus obras, sus escritos científicos o de divulgación se han utilizado en numerosas actividades de la Facultad, por parte de profesores y alumnos. Para nosotros queda por tanto una obra y no un mero recuerdo.

Con esta nota, no he pretendido elaborar un artículo científico, he prescindido de documentos y otros escritos; es posible quizás que se hayan deslizados algunos pequeños errores o que pueda haber alguna inexactitud en el terreno cronológico; pero como he indicado, sólo trataba de recoger los recuerdos sobre un gran maestro de un discípulo de Enrique Fuentes Quintana. 